Revista Brasileira de Meteorologia, v.29, n.3, 443 - 456, 2014

http://dx.doi.org/10.1590/0102-778620130595

\title{
O CENTRÓIDE DA PISCINA DE ÁGUA QUENTE DO PACÍFICO COMO UM INDICADOR DOS FENÔMENOS EL NIÑO E LA NIÑA
}

\author{
FABIO VIEIRA MACHADO, VICTOR DE AMORIM D’ÁVILA
}

\author{
Universidade do Estado do Rio de Janeiro (UERJ), Faculdade de Oceanografia, Rio de Janeiro, RJ, Brasil \\ fvmachado@gmail.com, victor.a.amorim@gmail.com
}

Recebido Fevereiro de 2013 - Aceito Novembro de 2013

\begin{abstract}
RESUMO
Os fenômenos oceanográficos El Niño e La Niña foram analisados através do monitoramento da série temporal da componente zonal do centroide da piscina de água quente do Pacífico (PAQ) que descreve movimentos leste-oeste ao longo da faixa intertropical deste oceano. Utilizou-se uma série de dados de temperatura da superfície do Oceano Pacífico para classificar a PAQ e estimar o seu centroide entre 1981 e 2003. Todos os episódios de El Niño (1982-83; 1986-87; 1990-95; e 1997-98) e La Niña (1984-85; 1988-89; 1998-2000) existentes no período analisado puderam ser observados na série temporal de dados da componente zonal da PAQ (CZPAQ). Os episódios mais intensos de El Niño foram classificados pela ordenação decrescente dos maiores deslocamentos para leste (ranking). A série de dados da CZPAQ se apresentou em fase com o índice de Oscilação Sul e com a anomalia da temperatura superficial do oceano (TSO). As flutuações associadas ao movimento zonal do centroide da PAQ foram observadas no espectro de energia onde ficaram ressaltadas as flutuações interanuais associadas aos fenômenos El Niño e La Niña. Foram observados deslocamentos mais curtos para oeste durante os anos de La Niña, quando comparados aos deslocamentos para leste durante os eventos de El Niño. A migração zonal da PAQ, representada aqui pelo centroide, apresentou-se, portanto, como um indicador dos fenômenos El Niño e La Niña. A principal vantagem dessa técnica é a dependência de um único parâmetro arbitrário, que é o limiar da TSO para delinear a PAQ.
\end{abstract}

Palavras-chave: El Niño, La niña, centroide, temperatura superficial dos oceanos.

\begin{abstract}
THE CENTROID OF THE PACIFIC WARM POOL AS AN INDEX FOR THE EL NIÑO AND LA NIÑA PHENOMENA

The El Niño - La Niña oceanographic phenomena were analized making use of the zonal component of the Pacific warm pool (PAQ) which describes east-west displacements along the intertropical belt of this ocean. We manipulated an ocean surface temperature (TSO) timeseries to classify the PAQ and to estimate its centroid between 1981 and 2003. All the El Niño $(1982-83$; 1986-87; 1990-95; e 1997-98) and La Niña $(1984-85 ; 1988-89 ; 1998-2000)$ episodes described in the academic literature were eminent in the timeserie of the zonal component of the Pacific warm pool (CZPAQ). The most intense El Niño episodes were ranked according to its furthest eastward displacement. The timeserie of the CZPAQ was in phase with both the TSO anomaly and the Southern Oscillation Index. The fluctuations associated to the CZPAQ were illustraded in the spectrum where interannual oscillations associated to the El Niño - La Niña phenomena were observed. Shorter migrations to the west during the La Niña years were notable in comparison to those eastward moviments during the El Niño events. Therefore, the zonal displacements of the PAQ, represented here by the centroid, were presented as having significant worth to indicate the El Niño and La Niña phenomena. The main advantage of this technique is that it depends on a single arbitrary parameter to represent the PAQ, the threshold of the ocean surface temperature in the Pacific Ocean.
\end{abstract}

Keywords: El Niño, La Niña, centroid, ocean surface temperature. 


\section{INTRODUÇÃO}

O El Niño é um fenômeno oceanográfico caracterizado pelo aquecimento das águas superficiais no oceano Pacífico equatorial central-leste (Cane, 1983; Philander, 1990). Esse fenômeno natural é capaz de alterar as condições climáticas em diversas partes do mundo resultando em catástrofes naturais em muitas dessas regiões (Grimm et al., 2000; Taschetto et al., 2011; Taschetto et al., 2009; Hill et al., 2009). Por estes motivos, esforços tem sido feitos para compreender as causas do fenômeno e quais seriam os mecanismos disparadores de cada evento (Ciasto e England, 2011; Sun, 2003; Delcroix et al., 2000). Essa questão é crucial à previsibilidade do fenômeno e tomadas de decisões evitando desastres sociais e econômicos em muitos países.

Uma descrição geral das características do fenômeno $E l$ Niño baseia-se em uma grande piscina de água quente (PAQ), que oscila em posição ao longo da faixa intertropical do Oceano Pacífico (McPhaden e Picaut, 1990; Picaut et al., 1996, 2002; Delcroix, 1998). Sabe-se que essa piscina afeta e é afetada pelos ventos alísios sazonais (Rasmusson e Wallace, 1983; McPhaden, 1999) envolvendo uma complexa dinâmica de interação entre o oceano e a atmosfera (Jin, 1996; Nofe Gorder, 1999; Delcroix et al., 2000). O movimento desta piscina para leste, por exemplo, corresponde a pelo menos, um relaxamento parcial dos alísios resultando em um aumento na temperatura das águas no Pacífico equatorial central-leste, particularmente durante os anos de El Niño, quando a PAQ descreve deslocamentos anômalos, possuindo um carácter episódico (Philander, 1990; Picaut et al., 1996; Delcroix, 1998). Isto está de acordo com Bjerkness $(1969,1972)$ quem propôs originalmente que durante o El Niño, os alísios e o gradiente zonal da temperatura superficial do oceano (TSO) Pacífico passam por uma anormalidade mútua. O fenômeno oposto, conhecido como La Niña, corresponde à intensificação dos alísios com empilhamento da PAQ no lado oeste e diminuição na temperatura das águas no setor leste deste oceano (Picaut et al., 2002; Chou et al., 2004; Machado e d'Ávila, 2006).

Na escala de tempo dos fenômenos El Niño e La Niña, estudos têm revelado que as maiores anomalias de convecção atmosférica, precipitação e ventos próximos à superfície são observadas no Pacífico equatorial central e oeste (Deser e Wallace, 1990; Lau et al., 1997). A convergência dos ventos em baixos níveis e a célula ascendente de convecção atmosférica seguem a trajetória zonal da PAQ durante as fases do ciclo $E l$ Niño - La Niña (Picaut et al., 1996; Delcroix, 1998; McPhaden, 1999; Picaut et al. 2002).

Ho et al. (1995) estimaram o movimento da PAQ fazendo uso da série de dados semanais do sensor AVHRR dos satélites do NOAA, entre 1982 e 1991. Yan et al. (1997) deram continuidade ao trabalho de Ho et al. (op.cit.) utilizando a série de dados até 1993. Os autores monitoraram a posição da PAQ calculando o seu ponto geográfico central, conhecido como centroide. Eles assumiram a piscina quente como uma superfície de água homogênea com temperatura superficial maior do que $28^{\circ} \mathrm{C}$ no interior de uma região de coordenadas geográficas $120^{\circ} \mathrm{E}-110^{\circ} \mathrm{W}$ e $30^{\circ} \mathrm{N}-30^{\circ} \mathrm{S}$. Os autores estimaram o movimento da PAQ calculando seu centroide da seguinte forma:

$$
\begin{gathered}
\bar{X}=\sum_{i=1}^{n} x_{i} / n \\
\bar{Y}=\sum_{i=1}^{n} y_{i} / n
\end{gathered}
$$

onde $\mathrm{x}_{i}$ é a componente zonal, $\mathrm{y}_{i}$ a meridional e $n$ é o número de pontos da PAQ com TSO maior que $28^{\circ} \mathrm{C}$ na imagem de satélite.

Machado e d'Ávila (2006) fizeram uso das coordenadas esféricas para definir o centroide e monitorar a posição da PAQ ao longo do tempo. Em seu trabalho, os autores não utilizaram limites geográficos arbitrários e consideraram a temperatura de $29^{\circ} \mathrm{C}$ como limiar para definir a PAQ. O centroide, ou ponto geográfico central da PAQ, em coordenadas esféricas foi definido pelas relações a seguir:

$$
\begin{aligned}
\varphi_{m} & =\tan ^{-1} \frac{\frac{\sum_{i=1}^{N} \sin \lambda_{i} a_{i}}{\sum_{i=1}^{N} a_{i}}}{\sqrt{\left(\frac{\sum_{i=1}^{N} \cos \varphi_{i} \cos \lambda_{i} a_{i}}{\sum_{i=1}^{N} a_{i}}\right)^{2}+\left(\frac{\sum_{i=1}^{N} \cos \varphi_{i} \operatorname{sen} \lambda_{i} a_{i}}{\sum_{i=1}^{N} a_{i}}\right)^{2}}} \\
\lambda_{m} & =\tan ^{-1} \frac{\frac{\sum_{i=1}^{N} \cos \varphi_{i} \operatorname{sen} \lambda_{i} a_{i}}{\sum_{i=1}^{N} a_{i}}}{\frac{\sum_{i=1}^{N} \cos \varphi_{i} \cos \lambda_{i} a_{i}}{\sum_{i=1}^{N} a_{i}}}
\end{aligned}
$$

onde $\varphi_{m}$ é a latitude, $\lambda_{m}$ a longitude do centroide (posição geográfica média) da PAQ, e $a_{i}$ é a área. Pela resolução espacial dos dados da TSO $(\Delta \mathrm{x} \Delta \mathrm{y})$ ser invariável $\left(1^{\circ} \mathrm{x} 1^{\circ}\right)$, a área é graduada pelo cosseno da latitude $\varphi_{i}$, considerando assim a terra esférica.

As relações previamente apresentadas calculam, portanto, a latitude e a longitude do centro geométrico da PAQ definida pelo limiar da TSO. Determinar a posição da PAQ e monitorar o seu deslocamento é importante para o entendimento dos fenômenos El Niño, La Niña e Oscilação Sul (entende-se este último como a componente atmosférica associada aos fenômenos oceanográficos El Niño e La Niña, ver Rasmusson e Wallace, 1983; Philander, 1990; Halpert e Ropelewski, 1992), uma vez que as oscilações da posição zonal desta piscina estão relacionadas às variações interanuais no Pacífico.

O objetivo deste trabalho é apresentar a componente zonal do centroide da PAQ como um índice para monitoramento dos fenômenos El Niño e La Niña. Desta forma, faz-se o uso das 
metodologias empregadas por Machado e d'Ávila (2006) para definir a temperatura limite da PAQ, calcular seu centroide em coordenadas esféricas, identificar os anos de El Niño e La Niña, e compará-los com os mais conhecidos índices de monitoramento desses fenômenos, como o Índice de Oscilação Sul (IOS) e a anomalia da temperatura superficial dos oceanos (ATSO).

Este trabalho foi divido em outras quatro partes. Na seção 2 é feita uma sucinta descrição dos dados utilizados, enquanto a metodologia empregada para a elaboração deste artigo é exposta em detalhes na seção 3. Nesta seção são apresentadas a técnica de Fourier aplicada e a relação para estimar o espectro de energia. Os resultados encontrados são discutidos na seção 4 deste estudo, sendo a conclusão apresentada na seção 5 .

\section{DESCRICAO DOS DADOS}

Foi feito uso de estimativas da TSO disponíveis pelo National Centers for Environmental Prediction (NCEP), com início em novembro de 1981 até fevereiro de 2003 (Reynolds et al., 2002). Essas estimativas resultam de uma combinação de dados procedentes de satélite, boias e navios de oportunidade para criar um campo global de médias mensais da TSO com resolução espacial de $1^{\circ}$ grau de latitude e longitude (Reynolds e Stokes, 2013). Os dados da TSO são utilizados para delimitar a PAQ no Oceano Pacífico e, consequentemente, calcular a posição zonal do centroide de acordo com a Equação 4. A série temporal analisada aqui permite estudar os principais episódios de El Niño e La Niña registrados nas duas últimas décadas do século passado.

O índice de Oscilação Sul (IOS) e da anomalia da TSO (ATSO) são utilizados para ilustrar o estado, ou fase, em que o Oceano Pacífico se encontra (condições de El Niño ou La Niña) e, logo, confrontar com a posição zonal do centroide. A ATSO representa a região do Pacífico delimitada pelas latitudes $0^{\circ}-10^{\circ} \mathrm{S}$ e longitudes $80^{\circ}-90^{\circ} \mathrm{W}$, conhecida como Niño $1+2$. As séries temporais do IOS e da ATSO cobrem o mesmo período do centroide da PAQ. Essas séries são disponíveis na internet na página do Climate Prediction Center em http://www.cpc. ncep.noaa.gov/data/indices/sstoi.indices para ATSO, e em http:// www.cpc.ncep.noaa.gov/data/indices/soi para o IOS.

Também são utilizados dados da isoterma de $20^{\circ} \mathrm{C}$ no Oceano Pacífico oriundos do programa para assimilação de informações oceânicas, descrita por Behringer et al. (1998). Esse sistema de informações resulta de uma combinação de dados obtidos por Expendable Bathythermograph (XBTs) e pelas boias do programa Tropical Ocean Global Atmosphere Tropical Atmosphere Ocean (TOGA-TAO) (McPhaden, 1993) para criar um campo espacial e temporal de análises oceânicas no Pacífico. Eles são utilizados aqui como aliados nas descrições dos processos migratórios da PAQ.

\section{METODOLOGIA}

Neste trabalho, fez-se uso de uma combinação das metodologias empregadas por Ho et al (1995), Yan et al. (1997) e Machado e d'Ávila (2006), onde a PAQ foi caracterizada como uma superfície de água homogênea. Além disso, baseado no trabalho de Machado e d'Ávila (op.cit.), considerou-se a esfericidade da Terra e o limiar de temperatura de $29^{\circ} \mathrm{C}$ para delinear a PAQ . O centroide da PAQ foi então definido como uma soma de vetores que apontam do centro da Terra para a superfície do Oceano Pacífico, onde a TSO descreve valores iguais ou maiores que $29^{\circ} \mathrm{C}$. A componente longitudinal do centroide, obtida pela Equação 4, foi analisada para identificar os anos de El Niño e La Niña e compará-los com os índices conhecidos de monitoramento desses fenômenos, como o IOS e a ATSO.

Os resultados obtidos com a estimativa da posição longitudinal do centroide da PAQ também foram organizados de acordo com as maiores migrações para leste (ranking). Assim, foi possível indicar os maiores deslocamentos longitudinais da PAQ e determinar sua persistência no Pacífico central-leste durante os eventos de El Niño mais prolongados, como o episódio de 1990-95, considerado o evento mais longo de todos os registros (Trenberth e Hoar, 1996).

A migração zonal do centroide da PAQ, durante o mais intenso e clássico episódio de El Niño - La Niña, entre os anos de 1997 e 1999 (McPhaden, 1999; Nicholls, 2000), foi associada ao comportamento da isoterma de $20^{\circ} \mathrm{C}$ na faixa equatorial do Pacífico e à série temporal dos índices de monitoramento desses fenômenos, com a finalidade de descrever os aspectos meteoceanográficos deste episódio.

As frequências associadas à migração da componente zonal do centroide da PAQ foram determinadas com a utilização da transformada de Fourier, onde uma dada densidade espectral associa determinada "quantidade de energia" a cada frequência do espectro.

\subsection{Transformada de Fourier (TF)}

As análises no domínio de frequência representam as séries de dados em termos de contribuições ocorrendo em diferentes escalas temporais, ou frequências características. Cada escala temporal é representada por um par de funções seno e cosseno. A análise harmônica consiste da representação de flutuações ou variações em uma série temporal que se originou da adição de uma série de funções seno e cosseno. Estas funções trigonométricas são harmônicas no sentido em que são escolhidas como tendo frequências que são múltiplas da frequência fundamental, determinada pelo tamanho amostral da série de dados. A série completa é considerada como 
resultante de efeitos combinados de um conjunto de ondas senoidais e cossenoidais, oscilando em diferentes taxas. A soma destas ondas reproduz os dados originais, mas comumente é a intensidade relativa das componentes individuais das ondas que são de interesse primário.

A TF na forma discretizada é um método bastante utilizado para extrair estimativas espectrais a partir de dados amostrados em intervalos regulares. Se uma função contínua $\mathrm{P}(\mathrm{x})$ é discretizada por amostragem de $\mathrm{N}$ pontos com intervalo $\Delta \mathrm{x}$, tem-se a TF e sua inversa de acordo com as relações a seguir:

$$
\begin{aligned}
& F_{p}(A)=\sum_{x=0}^{N-1} \frac{P(x)}{N} e^{-i(2 \pi A x / N)} \\
& P(x)=\sum_{A=0}^{N-1} \frac{F(A)}{N} e^{-i(2 \pi A x / N)}
\end{aligned}
$$

onde $\mathrm{A}(\mathrm{A}=0 ; 1 ; 2 ; \ldots ; \mathrm{N}-1)$ é a frequência, dada por oscilações por período total de amostragem. Desta forma, para cada coeficiente, $F p(A)$, é associado uma contribuição relativa ao A-ésimo harmônico. A frequência dada pelo primeiro valor, $F p(0)$, denota o valor médio da série original. A frequência fundamental $F p(1)$, significa que uma onda preenche exatamente o período de tempo completo determinado pelo tamanho amostral da série de dados. Certamente, a mais baixa frequência, relativa ao harmônico fundamental $A_{1}=2 \pi / N$, corresponde à onda cosseno que executa um ciclo inteiro sobre os $\mathrm{N}$ pontos da série. Frequências maiores correspondem aos harmônicos de ordem superior ou múltiplos da frequência fundamental. A mais alta frequência que pode ser resolvida na $\mathrm{T}_{\mathrm{F}}$ é $A_{N / 2}=\pi$, ou ainda $N_{f}=N / 2$, conhecida como frequência de Nyquist. Essa é a frequência da onda cosseno que executa um ciclo inteiro em apenas dois intervalos de tempo entre os dados igualmente espaçados, o que implica que executa $\mathrm{N} / 2$ ciclos sobre o comprimento inteiro de dados. Dessa forma, as frequências permitidas variam num intervalo entre $f_{l}=1 / \mathrm{N}$ para a frequência fundamental até $\left(f_{N / 2}=1 / 2\right)$ para a frequência de Nyquist.

Das expressões descritas anteriormente, a expressão 5 executa a transformada e cria uma representação do sinal em frequência (ou espaço de fase), processo conhecido como decomposição de Fourier. A expressão 6 executa a transformada inversa, convertendo o sinal em frequência para o espaço físico.

\subsection{Estimativa do espectro}

As características da série temporal obtidas por TF no domínio de frequência são comumente examinadas utilizando o gráfico de espectro de potência. Na sua forma mais simples, o gráfico de um espectro consiste das amplitudes ao quadrado como função da frequência $A$. A soma destes valores para todas as frequências resulta na variância total $\left(\sigma_{p}^{2}\right)$ da série temporal original:

$$
\sigma_{p}^{2}=\frac{1}{N} \sum_{x=0}^{N-1}(P(x)-\bar{P})^{2}=\sum_{x=0}^{N-1}\left|F_{p}\left(A_{x}\right)\right|^{2}
$$

Note que $\left|\mathrm{F}_{\mathrm{P}}(\mathrm{A})\right|^{2}$ pode ser interpretado como a porção da energia (ou variância) explicada pelas ondas de frequência $A$, ou seja, a intensidade da relação entre o $A$-ésimo harmônico e a série de dados é expressa inteiramente pela amplitude. Oscilações de frequência superiores à frequência de Nyquist não podem ser resolvidas e, por este motivo, são considerados apenas os valores para $\left|\mathrm{F}_{\mathrm{P}}(\mathrm{A})_{\mathrm{A}<\mathrm{N} / 2}\right|^{2}$, que são multiplicados por dois, com a finalidade de preservar a variância do sinal analisado, e divididos pelo intervalo de frequência, $\Delta A$, para fornecer a densidade de espectro de energia. No entanto, a maneira comum para descrever a frequência $A$ é em número de oscilações por unidade de tempo, resultando em $\Delta A=1 / T$, onde $T$ é o período total da série amostrada. Quando expressa em função da frequência f, o espectro é descrito pela relação 8:

$$
S_{p}(f)=\frac{2\left|F_{p}(f)_{f<N / 2 T}\right|^{2}}{\Delta f}
$$

A unidade de $S_{p}(f)$ é de energia (ou variância) por unidade de frequência.

\section{RESULTADOS E DISCUSSÃO}

A série temporal da componente zonal do centroide da PAQ, obtida em coordenadas esféricas, de acordo com a Equação 4, foi estudada para monitorar o movimento da PAQ, identificar os anos de El Niño e La Niña e compará-los com os índices conhecidos de monitoramento desses fenômenos, como o IOS e a ATSO.

Na Figura 1 são confrontadas a série temporal da componente zonal da PAQ (CZPAQ) com o IOS e a ATSO. É bastante clara a relação que existe entre os índices de monitoramento dos fenômenos El Niño e La Niña e o deslocamento zonal da PAQ.

Observam-se nessas séries temporais, os seguintes anos de El Niño: 1982-83; 1986-87; 1990-95; 1997-98. O fato é que ainda existem diferenças marcantes dentro de cada categoria. Por exemplo, os episódios de 1982-83 e 1997-98 foram considerados pela comunidade científica como os mais intensos do século passado (Philander, 1990; McPhaden, 1999; Delcroix et al., 2000; Nicholls, 2000; Picaut et al., 2002). De acordo com o IOS e a ATSO, o evento de 1982-83 apresentou um maior valor de anomalia, porém o episodio de 1997-98 foi considerado como o mais forte entre eles. O evento de 1986-87 foi considerado um evento moderado (McPhaden e Picaut, 1990; Philander, op.cit.), enquanto que o evento mais longo ocorreu entre 1990-95 (Trenberth e Hoar, 1996). Outros autores como Boo e Lim (2004), por exemplo, dividem o evento de 1990-95 em dois episódios: o primeiro corresponde aos anos de 1991-93; e o segundo de 1994-95. 

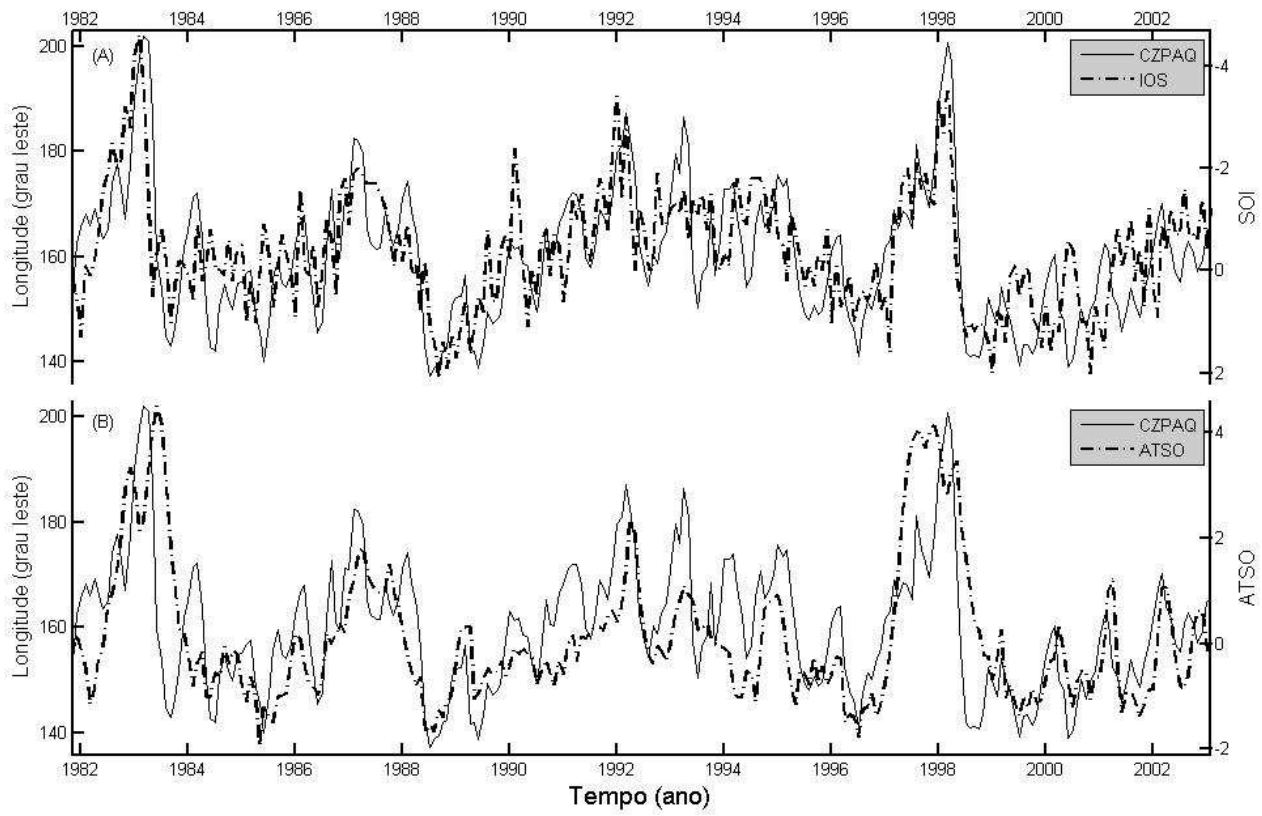

Figura 1 - Series temporais (A) IOS e CZPAQ; (B) ATSO e CZPAQ. As séries compreendem o período de novembro de 1981 a março de 2003.

Os eventos de 1982-83 e 1997-98 também descreveram os maiores deslocamentos da CZPAQ para leste, chegando a ultrapassar a longitude de $200^{\circ} \mathrm{E}$. Ou seja, em ambos os eventos, o centroide da PAQ alcançou a posição central do Pacífico. A CZPAQ alcança no máximo a região central do Pacífico durante esses eventos extremos de El Niño, uma vez que a água de $29^{\circ} \mathrm{C}$ preenche toda a faixa equatorial deste oceano, e o centroide representa o centro geométrico da piscina. Durante os episódios de 1986-87, 1991-93 e 1994-95, a CZPAQ apresentou um deslocamento menor para leste em relação aos eventos descritos acima, sendo que durante os anos de 1991-93 é observado o deslocamento mais a leste dentre esses. A média da posição zonal do centroide da PAQ fica em torno de $160,2^{\circ} \mathrm{E}$ de longitude.

Os seguintes anos de La Niña foram observados nas séries temporais analisadas: 1984-85; 1988-89; 1998-2000. Esses eventos foram indicados pelos mais positivos índices de Oscilação Sul, resultado de intensos ventos alísios ao longo da faixa equatorial do Pacífico (Philander, 1990; Deser e Wallace, 1990), pela anomalia negativa da TSO na região Nino1+2 causada pelo fenômeno da ressurgência costeira ao largo da costa Peruana (Halpern, 2002), pelo completo aprisionamento da PAQ no setor noroeste do Pacífico (Machado e d'Ávila, 2006; Yan et al., 1992) e consequente posicionamento da CZPAQ no oeste deste oceano.

Sabe-se que, em condições normais, as águas superficiais no Oceano Pacífico são mais quentes no setor oeste e mais frias no leste (Cane, 1983; Philander, 1985; Yan et al., 1992; Gu e Philander, 1995). No entanto, a temperatura da água ao largo da costa do Peru aumenta periodicamente no verão austral e alcança seu máximo entre Fevereiro e Março (dados de TSO disponíveis na página do Climate Prediction Centre, National Weather Service), concordando com o enfraquecimento dos alísios (Rasmusson e Wallace, 1983; Philander, 1990) e a interrupção do fenômeno da ressurgência (Philander, 1981; Halpern, 2002). Neste trabalho, o termo El Niño é reservado para os eventos naturalmente recorrentes de deslocamento anômalo da PAQ para leste, interrompendo o período de ressurgência costeira, com consequente aumento atípico na temperatura das águas superficiais ao longo de toda a faixa equatorial do Oceano Pacífico como por exemplo, os episódios de 1982-83 e 1997-98.

A transformada de Fourier foi calculada, de acordo com a Equação 5, para decompor o sinal da componente longitudinal da PAQ e representá-lo em termos de contribuição, que ocorrem em diferentes escalas temporais. Prontamente, foi feita uma análise do sinal no domínio da frequência fazendo uso do gráfico de espectro de potência, ilustrado na Figura 2, e calculado de acordo com a Equação 8, para determinar a intensidade relativa das componentes individuais.

Esse gráfico consiste, portanto, das amplitudes das componentes ao quadrado que são multiplicados por dois, para preservar a variância do sinal, e divididos pelo intervalo de frequência para estimar a densidade do espectro de energia. Pode-se notar no gráfico os principais modos de oscilação, que correspondem as componentes anual e interanuais.

Nenhum filtro foi utilizado para remover qualquer componente do sinal analisado porque é desejado obter o maior número de informações sobre o deslocamento zonal da PAQ. 


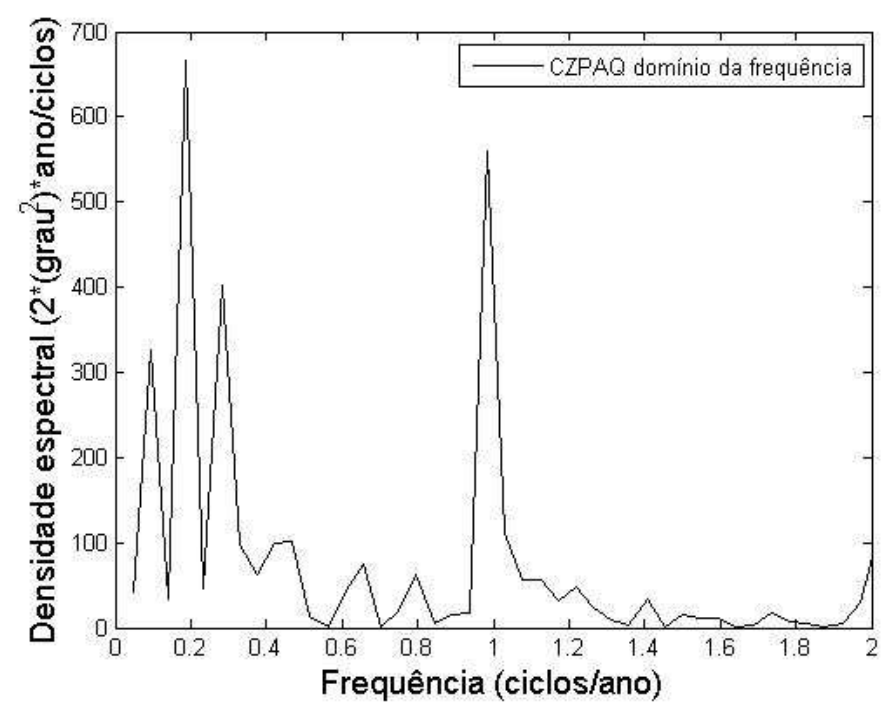

Figura 2 - Espectro de energia (potência) obtido pela transformada de Fourier do sinal da componente zonal da PAQ. A unidade é de variância por unidade de frequência.

Os maiores picos de energia do sinal obtido para a CZPAQ estão associados às seguintes flutuações: 10,6 anos (frequência fundamental) e; entre 3,5 e 1,5 anos que correspondem as oscilações interanuais associadas aos fenômenos El Niño e La Niña no Pacífico. Apesar do movimento zonal do centroide da PAQ descrever evidentemente as oscilações interanuais pertinentes aos fenômenos El Niño e La Niña, e o movimento meridional exibir claramente o ciclo anual relacionado a migração solar (Machado e d'Ávila, 2006; Yan et al., 1997; Ho et al, 1995), observa-se no espectro de energia uma intensa contribuição anual na migração zonal do centroide da PAQ. Isso indica que existe um deslocamento longitudinal periódico da CZPAQ na escala anual e que está provavelmente associado ao El Niño não científico, definido pelos pescadores Peruanos devido ao aquecimento periódico das águas superficiais no Pacífico leste.

Na Figura 3 estão representadas as frequências relativas acumuladas e o histograma para a posição zonal do centroide da $\mathrm{PAQ}$ em todo o período de análise. Os intervalos de classe foram obtidos a partir da relação, onde $\mathrm{N}$ é o número de medições feitas ao longo do período analisado e K é o número de classes.

Considerando a linha de mudança de data $\left(180^{\circ} \mathrm{E} / \mathrm{W}\right)$, nota-se que o centroide da PAQ permaneceu predominantemente no setor oeste do Oceano Pacífico. Para o período estudado, a componente zonal do centroide posicionou-se 239 vezes $(93,36 \%)$ à oeste da linha de mudança de data, e 17 à leste da mesma $(6,64 \%)$. Isso reforça o conceito reservado aqui para o El Niño como um fenômeno naturalmente recorrente de deslocamento anômalo da PAQ para leste. Como a PAQ é caracterizada por TSO acima de $29^{\circ}$, o movimento neste sentido reflete anomalias positivas na temperatura das águas no Pacífico central e leste.

Em relação à média da posição zonal do centroide $\left(\sim 160^{\circ} \mathrm{E}\right)$, observam-se deslocamentos bem mais curtos para oeste durante os anos de La Niña quando comparado com aqueles deslocamentos para leste durante os anos de El Niño. Isso ocorre porque a média da posição zonal da PAQ fica mais deslocada para a região oeste do Pacífico, dada pelo balanço dos ventos alísios sazonais, pelo gradiente zonal de TSO, pela gangorra barométrica com seus dois centros principais de ação no Pacífico, e pelos limites formados pelas barreiras continentais a oeste e leste (Hamza, et al. 2000). Os maiores deslocamentos longitudinais da PAQ para leste ocorrem, portanto, durante os anos de El Niño com espalhamento da piscina quente por toda a faixa intertropical do Oceano Pacífico. Esse aspecto oceanográfico permite, então, utilizar a componente zonal da PAQ como um indicador para este fenômeno.

Cabe ressaltar que quanto mais deslocado para leste o centroide encontra-se, maior sua posição longitudinal. Assim, a Tabela 1 apresenta a posição longitudinal do centroide da PAQ para cada mês em ordem decrescente (ranking). Esta tabela é dividida em 12 pares de colunas (correspondente aos 12 meses do ano), na qual cada par exibe a posição zonal da PAQ e seu ano correspondente. As colunas iniciam em Junho e terminam em Maio. A ordem decrescente indica no topo da tabela, portanto, os mais significantes deslocamentos para leste com seus respectivos anos, enquanto que os valores na parte inferior apontam o centroide localizado mais a oeste. Deste modo, os deslocamentos para leste foram graduados em cada mês.

Nota-se primeiramente que a PAQ permanece mais deslocada para o setor leste entre os meses de Janeiro e Abril, com posicionamento extremo em Março e Abril. Estes meses são aqueles indicativos do El Niño "científico" porque assinalam o maior espalhamento da PAQ para leste e a permanência da mesma por um tempo mais longo do que aquele episódio periódico anual ${ }^{1}$, refletindo em anomalias positivas da TSO nas regiões de monitoramento do fenômeno.

A tabela ainda permite classificar os eventos de El Niño e La Niña e suas intensidades de acordo com o deslocamento zonal do centroide da PAQ. Observa-se que os anos de 1983 e 1998, no topo da tabela, referentes aos episódios de 198283 e 1997-98, apresentaram os maiores deslocamentos para leste invariavelmente no mês de Março $\left(201,92^{\circ} \mathrm{E}\right.$ e $200,59^{\circ} \mathrm{E}$, respectivamente) e são considerados pela sociedade científica como os mais intensos episódios já registrados (Rasmusson e Hall, 1983; McPhaden, 1999; Delcroix et al., 2000; Nicholls, 2000). Os anos de 1986-87, 1991-93 apresentaram expressivos deslocamentos para leste, apesar de serem menos amplos

\footnotetext{
${ }^{1}$ Maiores detalhes sobre o El Niño periódico anual, ver Cane (1983), Philander (1990) e Hamza et al., 2002.
} 


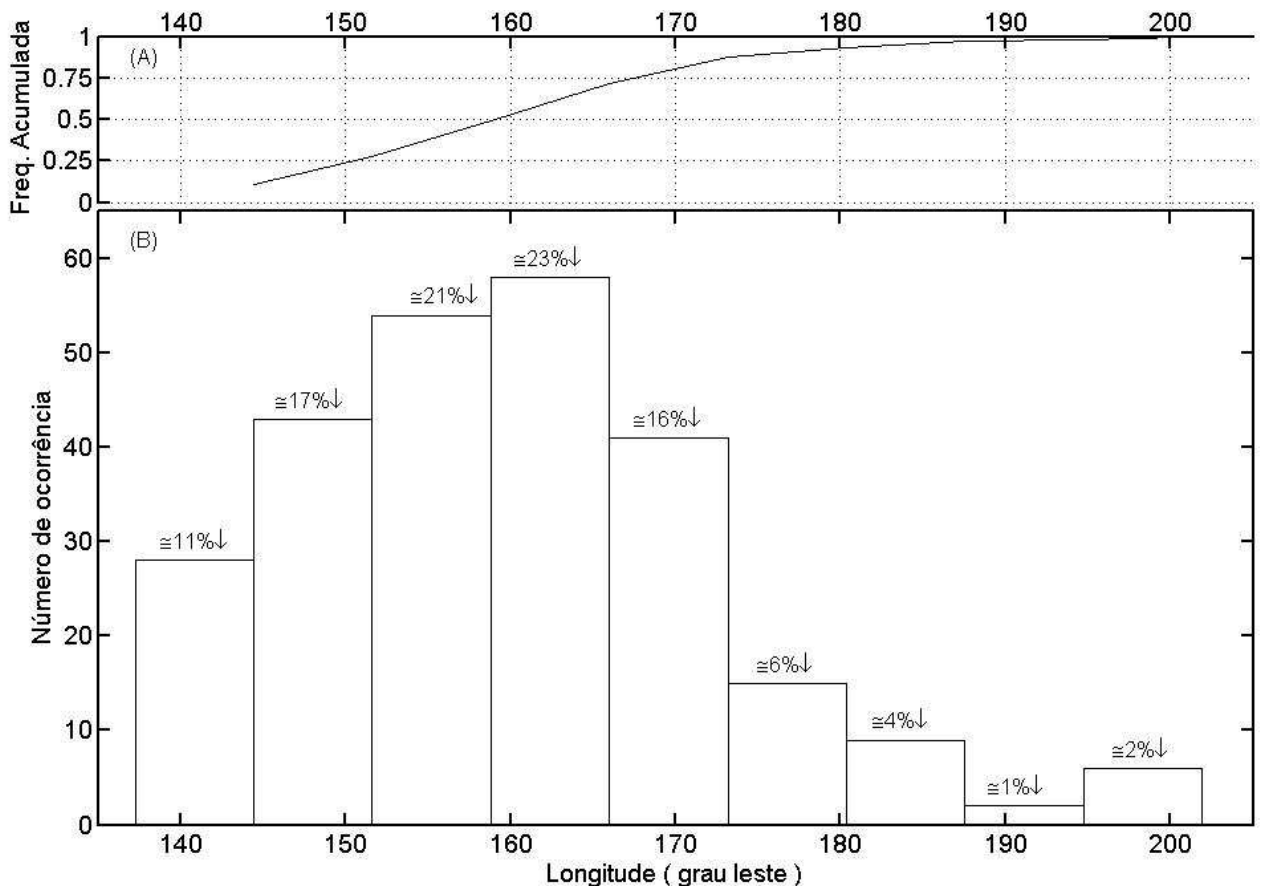

Figura 3 - (A) Frequência acumulada da posição zonal da PAQ e (B) histograma com 9 intervalos de classes iguais de amplitude 7,1844 . Dados mensais de Novembro de 1981 a Fevereiro de 2003.

quando comparados com os episódios de 1982-83 e 199798, e são considerados aqui e pela comunidade científica (Philander, 1990; Delcroix, 1998; Boo e Lim, 2004) como eventos moderados. Entre 1994 e 1995, a CZPAQ descreveu deslocamentos importantes para leste, porém bem menos significativos em comparação aos eventos apresentados anteriormente. Além disso, a ATSO e o IOS indicaram baixos índices para esse período. Por esses motivos, esse episódio pode ser avaliado como um evento consideravelmente fraco.

O centroide traça, então, uma trajetória com máximos deslocamentos da PAQ para leste durante os mais intensos episódios de El Niño (ver Figuras 5a e 5e em Machado e d'Ávila, 2006). Nesses anos, o centroide cruza a linha de mudança de data $\left(180^{\circ} \mathrm{E}\right)$ e alcança o posicionamento mais distante em Março, durante o outono austral. Esse indicador reforça o argumento de Gu e Philander (1995) onde é relatado que tais episódios afetam significativamente o ciclo anual no Pacífico tropical leste. $\mathrm{Ou}$ seja, em condições normais, a máxima taxa de aquecimento da água superficial na região do Pacífico leste ocorre em Janeiro (Hamza et al., 2000) e está associada ao aquecimento periódico anual dessas águas. Com o tempo mais longo para atingir o deslocamento mais distante para leste na faixa equatorial do Pacífico, o ciclo anual é afetado significativamente pelo fenômeno El Niño.

Na parte inferior da tabela, observam-se os anos que o centroide da PAQ indicou a posição mais deslocada para o oeste do Pacífico. Entre esses, destacam-se os anos de 1988, referente ao episódio de 1988-89, e 1998, referente ao evento de 19982000, considerados anos sob maior influência do fenômeno $L a$ Niña (Picaut e Delcroix , 1995; Johnson et al., 2000; Picaut et al., 2002). Os máximos deslocamentos da CZPAQ para oeste foram observados em 1988, quando o centroide chegou a alcançar a longitude de $137,26^{\circ} \mathrm{E}$ no mês de Julho.

Avaliando as posições da CZPAQ nos setores oeste e leste do Pacífico, fica notável observar que as maiores migrações zonais do centroide ocorreram na transição entre uma fase de El Niño para a fase La Niña, em particular, nos anos de 1983 e 1998, que corresponderam aos dois episódios de El Niño mais intensos com sequentes episódios de La Niña. Os maiores deslocamentos longitudinais da CZPAQ foram de $58,78^{\circ} \mathrm{em}$ 1983 e de $59,66^{\circ}$ em 1998 , de leste para oeste, quando as condições meteoceanográficas no Oceano Pacífico mudaram de fase.

A máxima variação zonal do centroide da PAQ foi estimada em $64,66^{\circ}$, quando considerado suas posições extremas $\left(137,26^{\circ} \mathrm{E}\right.$ e $\left.201,92^{\circ} \mathrm{E}\right)$. Esta amplitude do movimento zonal foi arbitrariamente dividida em 5 partes equivalentes (distância de $12,932^{\circ}$ ), nas quais foram encontrados os seguintes limites: 1) $137,26^{\circ}-150,192^{\circ}$; 2) $150,192^{\circ}-163,124^{\circ}$; 3) $163,124^{\circ}-$ $176,056^{\circ}$; 4) $176,056^{\circ}-188,988^{\circ} \mathrm{E}$; 5) $188,988^{\circ}-201,92^{\circ} \mathrm{E}$. A CZPAQ permaneceu no primeiro intervalo da trajetória $23,83 \%$ do tempo (61 vezes), no segundo intervalo 39,06\% (100 vezes); 
ব

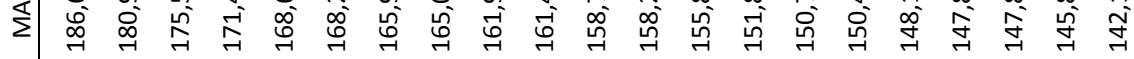
ऐ)⿱人从 × ष

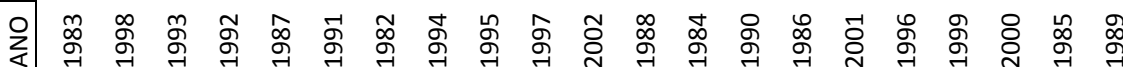
중

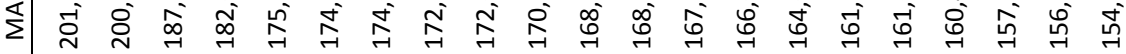

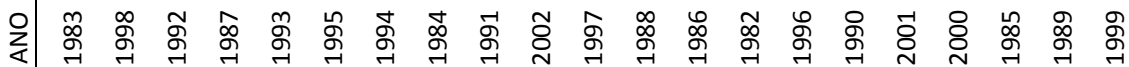
$>$ \)

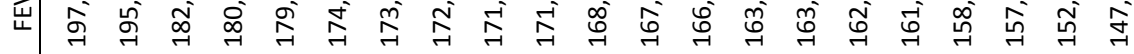
\) z

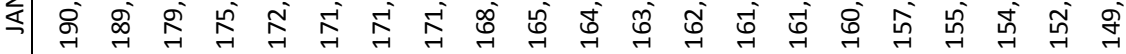

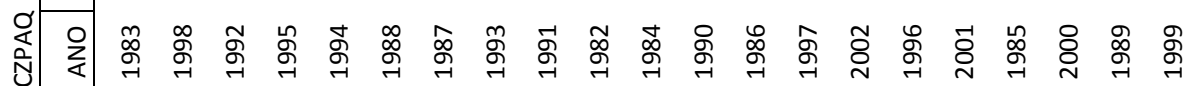

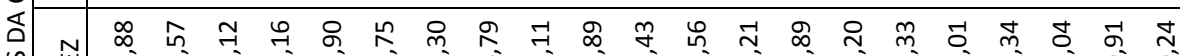

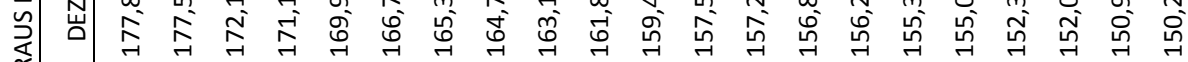
惢 >

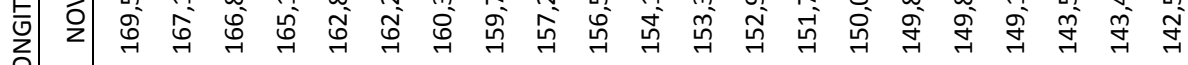

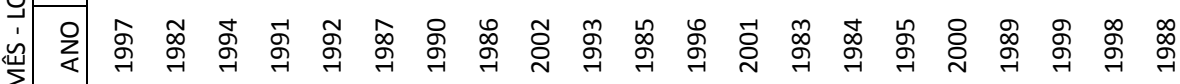

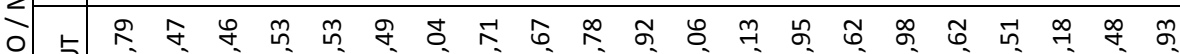

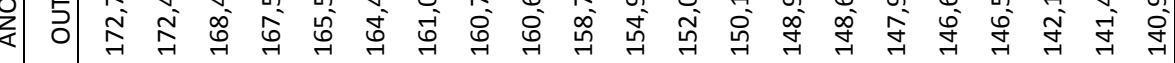

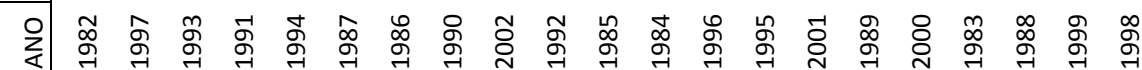
$\checkmark$ b 岀 苂 吉

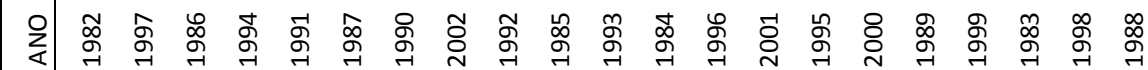
○) ᄀ 국

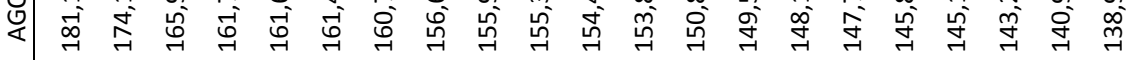

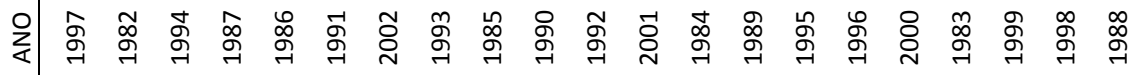

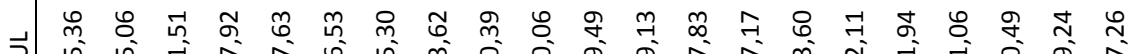

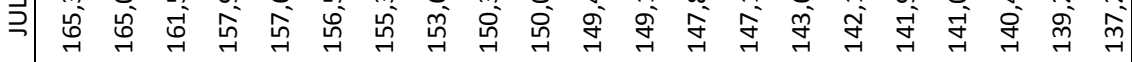

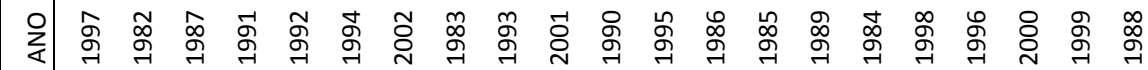
乙

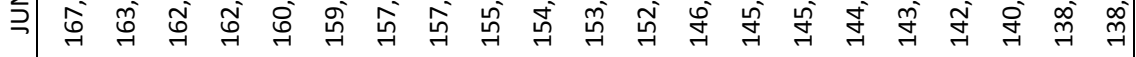
ऐ) 
no terceiro intervalo $28,12 \%$ (40 vezes); $5,86 \%$ (15 vezes) no quarto intervalo; e apenas $3,12 \%$ do tempo (8 vezes) a CZPAQ esteve presente no último intervalo da trajetória traçada. Desta forma, foi possível classificar a posição da CZPAQ em condições normais, de El Niño e de La Niña no Oceano Pacífico.

Primeiramente, nota-se que o quinto intervalo destaca exclusivamente os dois episódios mais intensos (1982-83 e 1997-98) durante os meses indicativos do El Niño "científico" (de Fevereiro a abril). Isso já corrobora com a justificativa da maior intensidade do fenômeno durante esses anos. A intensidade moderada para os eventos de El Niño pode ser observada no quarto intervalo, onde se ressaltam os deslocamentos para leste nos anos de 1987, 1992 e 1993, durante os episódios de 198687 e 1991-93.

Por outro lado, nota-se que o primeiro intervalo aparta uma faixa longitudinal onde se realçam os anos de La Niña, sobressaindo os anos de 1988-89 e 1998-2000, quando a CZPAQ alcançou as longitudes mais a oeste de toda a série de dados, entre Junho e Outubro. O segundo e o terceiro intervalos zonais $\left(150,192^{\circ} \mathrm{E}-176,056^{\circ} \mathrm{E}\right)$ da posição do centroide da PAQ ilustram as condições normais de oscilação da PAQ no Pacífico equatorial. Nesta faixa podem-se observar as flutuações relacionadas ao aquecimento e resfriamento periódico anual que ocorrem nas águas superficiais das regiões de monitoramento do Oceano Pacífico.

Todos os índices de monitoramento já citados aqui anteriormente apresentaram uma relação bastante significativa e descreveram juntos os aspectos do fenômeno El Niño, La Niña e Oscilação Sul. Conforme observado, os anos de 1982-83 e 199798 descreveram um ciclo clássico de El Niño - La Niña. Por este motivo, a Figura 4 apresenta a série temporal (correspondente a 24 meses, de Jan-1982(1997) até dez-1983(1998)) do IOS, da ATSO e da CZPAQ para os eventos mencionados.

Nota-se que os episódios estão bem evidenciados nos três métodos para monitoramento do fenômeno. Confirma-se, por exemplo, na Figura 4A, que há uma invariabilidade do máximo deslocamento da componente zonal do centroide da PAQ para leste em Março (ver também na Tabela 1). Observa-se que a CZPAQ percorreu uma trajetória bastante semelhante para os dois eventos. A correlação entre as séries temporais da CZPAQ para os dois eventos mais fortes supracitados (de Jan-1982 até dez-1983 / de Jan-1997 até dez-1998) é de 0.93.

Entretanto, analisando os indicadores da anomalia da TSO e da Oscilação Sul, observam-se algumas diferenças marcantes. Primeiramente, nota-se que há defasagens no tempo em que ocorrem os valores máximos (ou índices extremos) para cada episódio ${ }^{2}$. Em anos de El Niño, por exemplo, a ATSO

\footnotetext{
2. A correlação entre as séries temporais da ATSO para os dois episódios é de 0,49 . A correlação entre as séries temporais do IOS para os dois episódios é de 0,8 .
}

indicou os seus máximos positivos de $4,49^{\circ} \mathrm{C}$ em agosto de 1983 , durante o episódio de $1982-83$, e de $4.13^{\circ} \mathrm{C}$ em janeiro de 1998 durante o episódio de 1997-98 (Figura 4B). Já o IOS realçou seus mínimos de -4,6 em fevereiro de 1983 e -3,5 em março de 1998. Ou seja, nenhum desses índices indicou seus valores extremos na mesma época do ano. Outra característica significante é a intensidade de cada episódio. O episódio de 1997-98 é considerado como o evento de maior intensidade de todos os tempos (McPhaden, 1999; Delcroix et al., 2000; Nicholls, 2000). No entanto, esses índices indicam seus valores extremos para o evento de 1982-83. Isso realça a incerteza desses índices para indicarem os eventos de El Niño de maior intensidade. Portanto, um valor extremo desses índices ou anomalias não corresponde necessariamente ao evento de maior intensidade.

A vantagem do método da componente zonal do centroide da PAQ, aqui proposto, para indicar e monitorar os fenômenos El Niño e La Niña no Oceano Pacífico, é sua independência de uma base climatológica para determinar uma média e sua anomalia (ou seu desvio em torno desta média). Além disso, há uma vantagem significativa neste método de depender apenas de um único parâmetro arbitrário, que é definir o limiar da temperatura superficial no Oceano Pacífico para representar a PAQ. Analisar a área preenchida pela PAQ durante episódios semelhantes, como os de 1982-83 e 1997-98, é crucial para melhor definir as intensidades de cada evento de El Niño (Machado e d'Ávila, 2006), pois a atmosfera global é extremamente sensível a TSO e, consequentemente, a posição da PAQ. Isso se deve ao fato desta piscina apresentar uma ampla área de água quente (Machado e d'Ávila, op. cit.; Yan et al., 1992) e devido a troca de calor turbulento entre o oceano e a atmosfera ser uma função não-linear da TSO (Yan et al., op. cit; Roberts et al., 2012).

Sabendo-se que a fase negativa da Oscilação Sul (ou IOS negativo) e a anomalia positiva da TSO assinalam os anos de El Niño, pode-se agregar ao conteúdo o processo migratório da PAQ e a variação da isoterma de $20^{\circ} \mathrm{C}$ ao longo da faixa equatorial do Oceano Pacífico ${ }^{3}$.

Se os ventos sobre o Pacífico equatorial diminuem de intensidade, o oceano tende a se ajustar em busca de um novo equilíbrio. Assim, a água quente acumulada no setor oeste flui para o leste na forma de uma onda de Kelvin equatorial (Harrison e Schopf, 1984; Zebiak e Cane, 1987; Philander, 1990). A PAQ espalha-se e preenche toda a faixa equatorial do Pacífico. Este processo provoca a subsidência da termoclina no lado leste deste oceano (Figura 5A), normalmente rasa nesta região (Figura 5B), e resulta em índices positivos da anomalia da TSO nas regiões de monitoramento do fenômeno

\footnotetext{
3. A profundidade da isoterma de $20^{\circ} \mathrm{C}$ ao longo da faixa equatorial representa uma média entre as latitudes de $5^{\circ} \mathrm{N}$ e $5^{\circ} \mathrm{S}$.
} 

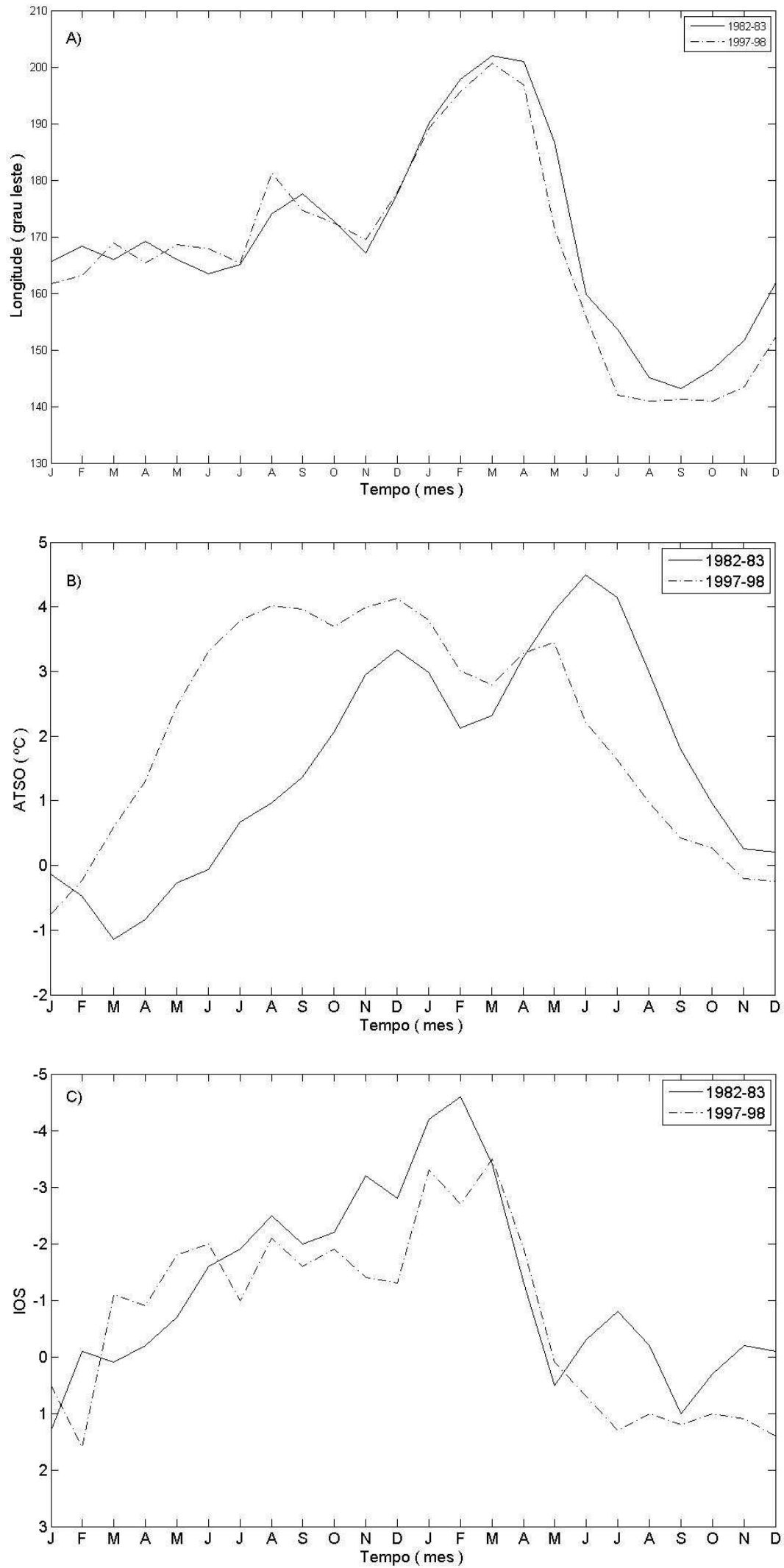

Figura 4 - Series temporais para os episódio de El Niño de 1982-83 (linha contínua) e 1997-98 (linha tracejada): (A) componente zonal do centroide da PAQ; (B) ATSO; (C) IOS. 


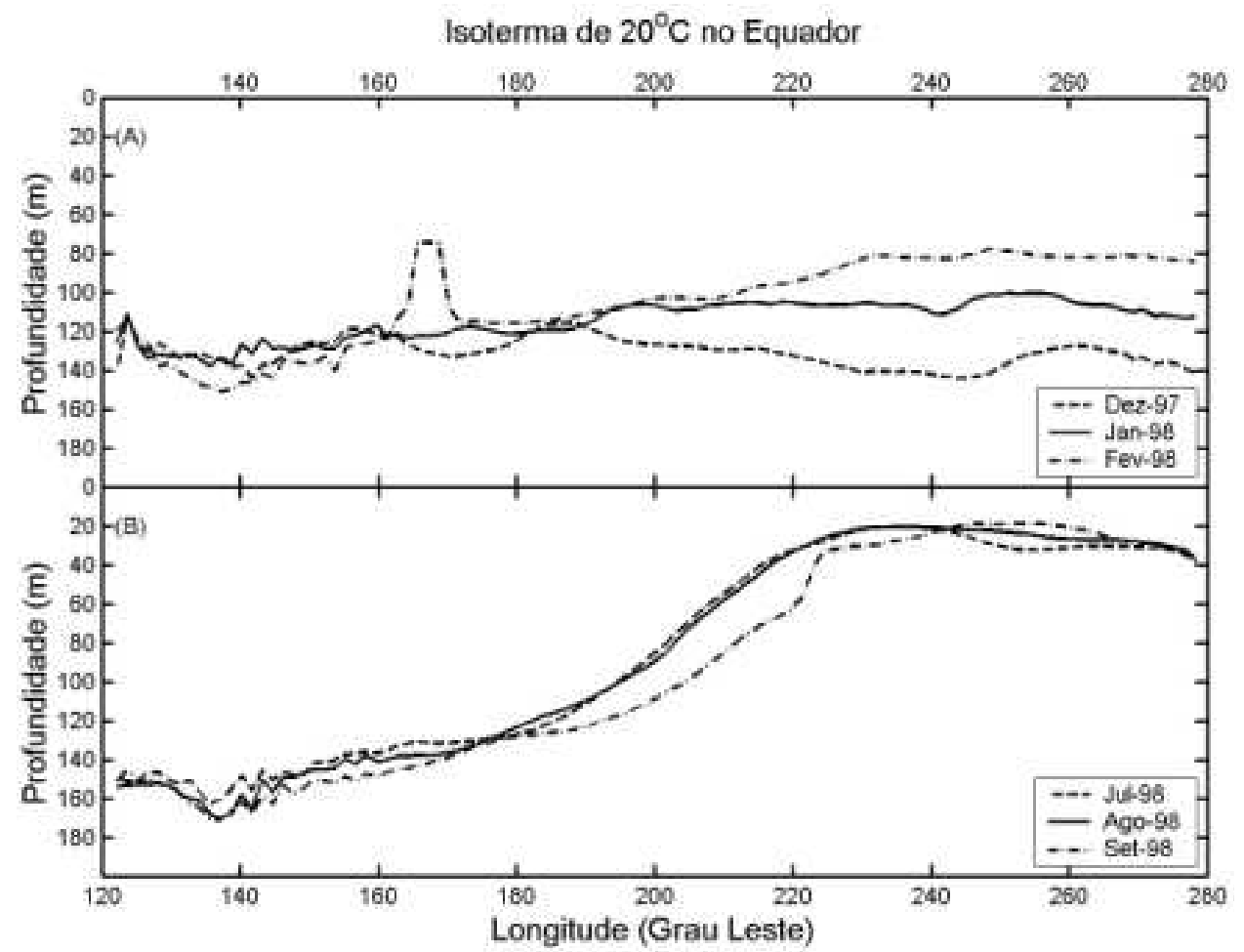

Figura 5 - Isoterma de $20^{\circ} \mathrm{C}$ ao longo da faixa equatorial do Oceano Pacífico. (A) Dezembro de 1997, Janeiro e Fevereiro de 1998: característica oceanográfica em condições de El Niño; (B) Julho, Agosto e Setembro de 1998: característica oceanográfica em condições de La Niña.

com impactos nos campos de pressão e ventos sobre o Pacífico tropical (Lau et al., 1997; Philander, 1990; Rasmusson e Wallace, 1983). De uma maneira geral, quando a ATSO é observada positiva e o IOS negativo, o centroide da PAQ esta deslocado para a região central do oceano e a isoterma de $20^{\circ} \mathrm{C}$ alcança a profundidade da ordem de $10^{2}$ metros. Todos esses indicadores juntos descrevem, de certa forma, a mesma história.

Por outro lado, sabe-se também que a fase positiva da Oscilação Sul (ou IOS positivo) e correspondente anomalia negativa da TSO no Pacífico leste apontam os anos de La Niña. Com a intensificação dos ventos alísios, a PAQ fica aprisionada no extremo oeste do Pacífico refletindo nos menores valores longitudinais da CZPAQ. Além disso, a isoterma de $20^{\circ} \mathrm{C}$ alcança aproximadamente a profundidade de 180 metros nessa região (Figura 5B). No setor leste do oceano, a isoterma de $20^{\circ} \mathrm{C}$ aflora e permite uma diminuição da TSO em superfície, assinalando um índice negativo da sua anomalia. Como mencionado anteriormente, os anos de 1988-89 e 1998-1999, por exemplo, configuraram as condições de La Niña como fase complementar do ciclo El Niño - La Niña (Philander, 1990; Nicholls, 2000; Delcroix et al., 2000; Picaut et al., 2002). Gu e Philander (1995) mostraram que o ciclo anual apresenta uma menor amplitude durante um El Niño do que durante uma La Niña. Os autores concluíram que as flutuações da profundidade da termoclina, tal como a subsidência durante o El Niño e a ressurgência durante a La Niña, afetam o ciclo anual significativamente no Pacífico tropical leste. As analises ainda indicaram que uma forte fase fria ( La Niña), assinalada pelo fenômeno da ressurgência, realça a variação anual da TSO, enquanto que a fase quente (El Niño) tende a enfraquecer o ciclo anual. Esse movimento oscilatório da PAQ entre os setores leste e oeste, com consequentes flutuações da ATSO, do IOS e da profundidade da isoterma de $20^{\circ} \mathrm{C}$ alteram, portanto, as características atmosféricas e oceanográficas no Pacífico tropical com reflexos em diversas partes do mundo.

\section{CONCLUSÃO}

Todos os episódios de El Niño (1982-83; 1986-87; 1990-95; e 1997-98) e La Niña (1984-85; 1988-89; e 19982000), existentes no período analisado, foram observados na série temporal da componente zonal da PAQ. Os maiores deslocamentos da CZPAQ para leste indicaram os mais intensos episódios de El Niño, enquanto que as maiores migrações para oeste sugeriram anos em condições de La Niña no Oceano Pacífico.

A série temporal da componente zonal do centroide da PAQ se apresentou em fase com o IOS e a ATSO. Anomalia positiva da TSO na região Nino1+2 e o índice negativo da 
Oscilação Sul coincidem com o deslocamento da CZPAQ para leste e afundamento da isoterma de $20^{\circ} \mathrm{C}$ (da ordem de $10^{2} \mathrm{~m}$ ) ao longo do setor leste da região equatorial do Oceano Pacífico. Inversamente, a anomalia negativa da TSO na região Nino1+2 e o índice positivo da Oscilação Sul concordam com o deslocamento da CZPAQ para oeste e afloramento da isoterma de $20^{\circ} \mathrm{C}$ ao longo do setor leste do Oceano Pacífico.

As flutuações associadas ao movimento zonal do centroide da PAQ foram observadas no espectro de energia, onde ficaram ressaltadas as flutuações interanuais entre 3,5 e 1,5 anos associadas aos fenômenos El Niño e La Niña. Apesar do movimento zonal do centroide da PAQ descrever evidentemente as oscilações interanuais pertinentes aos fenômenos El Niño e La Niña, observa-se no espectro de energia uma intensa contribuição anual na migração zonal do centroide da PAQ. Isso indica que existe um deslocamento longitudinal da CZPAQ na escala anual e que está provavelmente relacionado com o aquecimento periódico das águas superficiais no Pacífico leste associado ao El Niño não científico.

Os episódios de El Niño e La Niña foram classificados pela ordenação decrescente dos deslocamentos da CZPAQ para leste (ranking). Os eventos mais intensos de El Niño apresentaram os maiores deslocamentos da CZPAQ para leste, enquanto os anos sob condições de La Niña exibiram as maiores migrações da CZPAQ para oeste. Entre Dezembro e Maio concordam como sendo os meses mais significativos para indicar os episódios de El Niño, enquanto que os anos de $\mathrm{La}$ Niña são apontados entre Julho e Outubro.

De acordo com as séries temporais analisadas, os episódios de 1982-83 e 1997-98 foram os mais intensos episódios de El Niño. Esses episódios começaram a se formar entre Julho e Novembro alcançaram seu máximo deslocamento invariavelmente no mês de Março do ano sequente, decaindo bruscamente até, aproximadamente, nos meses Julho e Setembro.

O episódio mais prolongado ocorreu entre 1990 e 1995 (1990-95), com início entre Agosto e Setembro de 1990 e término em Maio de 1995. Seus máximos foram observados entre Dezembro de 1991 e Maio de 1993 (1991-93). Os anos 1988-89 e 1998-2000 realçam os mais significantes episódios de La Niña.

Foram observados deslocamentos mais curtos para oeste durante os anos de La Niña, quando comparados aos deslocamentos para leste durante os eventos de El Niño. A migração zonal da PAQ, representada aqui pelo centroide, apresentou-se, portanto, como um significante indicador dos fenômenos El Niño e La Niña. As principais vantagens dessa técnica, com relação aos demais métodos utilizados são: a dependência de um único parâmetro arbitrário, que é o limiar da temperatura superficial no Oceano Pacífico para delinear a
PAQ; e sua independência em se criar uma base climatológica para se determinar médias e anomalias.

\section{AGRADECIMENTOS}

O primeiro autor agradece à FAPERJ (E-26/151.847/1999) e ao CNPq (Proc. 131084/2003-8) pelo apoio dado a este estudo. Os autores agradecem aos revisores e editores da RBMet que muito contribuíram para a melhoria deste trabalho.

\section{REFERÊNCIAS BIBLIOGRÁFICAS}

BEHRINGER, D. W.; JI, M.; LEETMAA, A. An Improved coupled model for ENSO prediction and implications for ocean initialization. Part I: The ocean data assimilation system. Monthly Weather Review, v. 126, p. 1013-1021, 1998.

BJERKNES, J. Atmospheric teleconnection from the Equatorial Pacific. Monthly Weather Review, v. 97, n. 3, p. 163-172, 1969.

BJERKNES, J. Large-scale atmospheric response to the 1964-65 Pacific Equatorial warming. Journal of Physical Oceanography, v. 2, p. 212-217, 1972.

BOO, K.-O.; LIM, G.-H. On the low-level circulation over the western north Pacific in relation with the duration of El Niño. Geophysical Research Letters, v. 31, L10202, 2004. CANE, M. A. Oceanographic events during El Niño. Science, v. 222, n. 4629, p. 1189-1195, 1983.

CIASTO, L. M.; ENGLAND, M. H. Observed ENSO teleconnections to Southern Ocean SST anomalies diagnosed from a surface mixed layer heat budget, Geophysical Research Letters, v. 38, L09701, 2011.

CHOU, S.-H; CHOU, M.-D.; CHAN, P.-K.; LIN. P.-H.; WANG, K.-H. Tropical warm pool surface heat budget and temperature: contrasts between 1997-98 El Niño and 1998-99 La Niña. Journal of Climate, v. 17, n. 9, p. 18451858, 2004.

DELCROIX, T. Observed surface oceanic and atmospheric variability in the tropical Pacific at seasonal and ENSO time scales: A tentative overview. Journal of Geophysical Research, v. 103 (C11), p. 18611-18633, 1998.

DELCROIX, T.; DEWITTE, B.; DU PENHOAT, Y.; MASIA, F.; PICAUT, J. Equatorial wave and warm pool displacements during the 1992-1998 El-Niño Southern Oscillation events: observation and modeling. Journal of Geophysical Research, v. 105 (C11), p. 26045-26062, 2000.

DESER, C.; WALLACE, J. Large-scale atmospheric circulation features of the warm and cold episodes in the tropical Pacific. Journal of Climate, v. 3, p. 1254-1281, 1990. 
GRIMM, A.M.; BARROS, V.R.; DOYLE, M.E.. Climate variability in Southern South America associated with El Niño and La Niña events. Journal of Climate, v. 13, p. 35-58, 2000.

GU, D.; PHILANDER, S.G.H. Secular changes of annual interannual variability in the tropics during the past century. Journal of Climate, v. 8, p. 864-876, 1995.

HALPERN, D. Offshore Ekman transport and Ekman pumping off Peru during the 1997-98 El Niño. Geophysical Research Letters, v. 29, n. 5, p. 19[1]-19[4], 2002.

HALPERT, M.S.; ROPELEWSKI, C.F. Surface temperature associated with the Suthern Oscillation. Journal of Climate, v. 5, p. 577-593, 1992.

HAMZA, V. M.; D’ÁVILA, V.A.; ULUGERGERLI, E. U. Use of interactive web tools in teaching geophysics in developing countries. Seismological Research Letters, v. 22, n. 5, p. 519-529, 2000.

HARRISON, D. E.; SCHOPF, P. S. Kelvin-wave-induced anomalous advection and onset of surface warming in El Niño events. Monthly Weather Review, v. 112, p. 923-933, 1984.

HILL, K. J.; TASCHETTO, A. S.; ENGLAND, M. H. South American rainfall impacts associated with inter-El Niño variations. Geophysical Research Letters, v. 36, L19702, 2009.

HO, C.-R.; YAN, X.-H.; ZHENG, Q. Satellite observations of upper-layer variabilities in the in the western Pacific warm poll. Bulletin of the American Meteorological Society, v. 76, p. 669-679, 1995.

JIN, F.-F. Tropical ocean-atmosphere interaction, the Pacific cold tongue, and the El Niño-Southern Oscillation. Science, v.274, n5284, p. 76-78, 1996.

JOHNSON, G. C.; MCPHADEN, M. J.; ROWE, G. D.; MCTAGGART, K. E. Upper equatorial Pacific Ocean current and salinity variability during the 1996-1998 El Niño-La Niña cycle. Journal of Geophysical Research, v. 105 (C11), 1037-1053, 2000

LAU, K.; WU, H; BONY, S. The role of large-scale atmospheric circulation in the relationship between tropical convection and the sea surface temperature, Journal of Climate, v. 10, p. 381-392, 1997.

MACHADO, F. M.; D’ÁVILA, V.A. A trajetória e área da piscina de água quente do Pacífico. Revista Brasileira de Meteorologia, v. 21, n.2, 2006.

MCPHADEN, M.J.; PICAUT, J. El Niño-Southern Oscillation displacements of the western equatorial Pacific warm pool. Science, v. 250, p. 1385-1388, 1990.

MCPHADEN, M.J. Genesis and evolution of the 1997-98 El Niño. Science, v. 283, p. 950-954, 1999.

MCPHADEN, M. J. TOGA-TAO and the 1991-93 El NinoSouthern Oscillation Event, Oceanography, v. 6, n. 2, p. 36-44, 1993.
NICHOLLS, N. El Niño/Southern Oscillation: aftermath of the 1997/1998 event and prediction of future events.Bulletin of the American Meteorological Society, v. 49, n. 3, p. 267-270, 2000.

NOF, D.; GORDER, S.V. Intense nonlinear migration of the Pacific warm pool. Deep-Sea Research Parts I, v. 46, p. 1705-1731, 1999.

PHILANDER, S.G.H. El Niño, La Niña, and the Southern Oscillation. Academic Press, 1990, 293 pp.

PHILANDER, S. G. H. El Niño and La Niña. Journal of The Atmospheric Sciences, v. 42, n. 23, p. 2652-2662, 1985.

PHILANDER, S. G. H. The response of equatorial oceans to a relaxation of the trade winds. Journal of Physical Oceanography, v.11, n. 2, p. 176-189, 1981.

PICAUT, J.; DELCROIX, T. Equatorial wave sequence associated with warm pool displacements during the 19861989 El Niño-LaNiña. Journal of Geophysical Research, v. 100 (C9), p. 18393-18408, 1995.

PICAUT, J.; HACKERT, E.; BUSSALACCHI, A. J.; MURTUGUDDE, R.; LAGERLOEF, G. S. E. Mechanism of the 1997-98 El Niño-La Niña, as inferred from spacebased observations. Journal of Geophysical Research, v. 107 (C5), p. 5[1]-5[20], 2002.

PICAUT, J.; LOUALALEN, M; MENKES, C.; MCPHADEN, M.J. Mechanism of the zonal displacements of the Pacific warm pool: implications for ENSO. Science, v. 274, p. 1486-1489, 1996.

RASMUSSON, E.M.; HALL, J.M.. The major Pacific warm episode of 1982/93. Bulletin of the American Meteorological Society, v. 32, n. 4, p. 301-306, 1983.

RASMUSSON, E.M.; WALLACE, J.M. Meteorological aspects of the El Nino/Southern Oscillation. Science, v. 222, n. 4629, p. 1195-1202, 1983.

REYNOLDS, R.W.; RAYNER, N.A.; SMITH, T.M.; STOKES, D.C.; WANG, W. An improved in situ and satellite SST analysis for climate. Journal of Climate, v. 15, p. 16091625, 2002.

REYNOLDS, R. W.; STOKES, D. C. Description of the OI. v2 monthly SST analysis ( $v 2$ indicates version 2). Maryland: National Center for Environmental Prediction. 17 Aug. 2012. 3p. Disponível na Internet. ftp://ftp.emc.ncep.noaa.gov/cmb/ sst/oimonth_v2/OIv2_monthly.info.asc 14 fev. 2013.

ROBERTS, J. B.; ROBERTSON, F. R.; CLAYSON, C. A.; BOSILOVICH, M. G. Characterization of Turbulent Latent and Sensible Heat Flux Exchange between the Atmosphere and Ocean in MERRA. Journal of Climate, v.25, 821-838, 2012.

SUN, D-Z. A possible effect of an increase in the warm-pool SST on the magnitude of El Niño warming. Journal of Climate, v. 16, p. 185-205, 2003. 
TASCHETTO, A. S.; UMMENHOFER, C. C.; SEN GUPTA, A.; ENGLAND, M. H. Effect of anomalous warming in the central Pacific on the Australian monsoon, Geophysical Research Letters, v. 36, L12704, 2009.

TASCHETTO, A. S.; SEN GUPTA, A.; HENDON, H. H.; UMMENHOFER, C. C.; ENGLAND, M. H. The contribution of Indian Ocean sea surface temperature anomalies on Australian summer rainfall during El Niño events. Journal of Climate, 24(14), p. 3734-3747, 2011.

TRENBERTH, K.E.; HOAR, T.J. The 1990-1995 El NiñoSouthern Oscillation event : longest on record. Geophysical Research Letters, v. 101, p. 57-60, 1996.
YAN, X.-H.; HE, Y.; LIU, W.T.; ZHENG, Q.; HO, C.-R. Centroid motion of the western Pacific warm pool during three recent El Niño-Southern Oscillation events. Journal of Climate, v. 27, p. 837-845, 1997.

YAN, X.-H.; KLEMAS, V.; CHEN, D. The western pacific warm pool observed from Space. Eos, v. 73, n. 4, p. 41-44, 1992.

ZEBIAK, S. E.; CANE, M. A. A model El Niño-Southern Oscillation. Monthly Weather Review, v. 115, p. 22622278, 1987. 